\title{
LAUDATIO PARA ERIK JAYME - MEMÓRIAS E UTOPIA
}

Entregado Título de Doutor Honoris causa pela UFRGS

Porto Alegre (Brasil), 14.03.2003 por Claudia Lima Marques,

Professora Titular de Direito Internacional Privado da UFRGS

Coordenadorado PPGDir./UFRGS, Doutora em Direito(Heidelbery)

Magnífica Reitora da Universidade Federal do Rio Grande do Sul, Professora Doutora Wrana Maria Panizzi

Exmo.Sr. Vice-Reitor Prof. Dr. José Carlos Hennemann

Excelentíssimo Senhor Diretor da Faculdade de Direito, Plínio de Oliveira

Excelentíssimo Senhor Vice-Diretor da Faculdade de Direito, Prof. Sérgio José Porto

Caríssimo Prof. Dr. Dr. h. c. mult. Erik Jayme,

Caríssimos Conselheiros do Conselho Universitário da Universidade Federal do Rio Grande do Sul

Senhoras e Senhores presentes

É com grande prazer e honta que apresento o mestre, Prof. Dr. Dr. h. c. mult. Erik Jayme, Professor Titular emérito da Universidade de Heidelberg e Diretor do Instituto de Direito Estrangeiro e Direito Internacional Econômico e Privado daquela Universidade co-irmã, justamente quando a Universidade Federal do Rio Grande do Sul oferece a este grande professor o título de Doutor Honoris causa UFRGS.

Erik Jayme, Professor catedrático de Direito Internacional Privado, Direito Comparado e Direito Civil da Universidade de Heidelberg é um dos maiores juristas de nossa época, internacionalista reconhecido mundialmente, famoso por seu brilhantismo e por seu profundo humanismo.

Com especial carinho pelo Brasil e pela UFRGS, contribuiu em muito para a manutenção e desenvolvimento do Convênio de Cooperação entre a Universidade 
de Heidelberg e a UFRGS e, especialmente, para o Programa de Pós-Graduação em Direito/ UFRGS, onde ajudou a criar a linha de pesquisa sobre direito e pós-modernidade. Minha tarefa aqui é apresentar este que, em sua aula magna de despedida de 16 de julho de $2002,{ }^{5} \mathrm{em}$ Heidelberg, foi aplaudido de pé por toda a universidade e ovacionado pelos estudantes, enquanto o Reitor da Ruperto Carola, Prof. Dr. Dr. Peter Hommelhoff, homenageava-o denominando o verdadeiro Ministro da Relações Exteriores da Universidade de Heidelberg. Efetivamente, Erik Jayme, com sua original doutrina, seu engajamento pela academia e sua abertura para o mundo, transcende a Faculdade de Direito ou o Instituto de Direito Estrangeiro, que por tantos anos dirigiu.

Erik Jayme reúne as qualidades dos grandes mestres, uma formação geral humanística, incluíndo 8 línguas e arte, uma cultura formidável, uma visão de presente realista e crítica, com um pensamento voltado - de forma muito ímpar - para o futuro. Sua aula magna de despedida tinha como título "Memótias e Utopia", que , com a vênia do mestre, utilizarei para dividir esta pequena exposição.

\section{I- MEMÓRIAS}

$\mathrm{Na}$ entrevista que concedeu a Revista Trimestral de Direito Civil, na seção Diálogo com a Doutrina, Erik Jayme testemunhava sua paixão pelo Direito Comparado e o Direito Internacional Privado, suas disciplinas de especialidade, afirmando: "Oque meprendéé redidade, o destino bumano(Schicksale), os caminhos eproblemas dos indivíduos." 2 Os caminhos de Erik Jayme não poderiam ter sido mais férteis:

Nascido no Canadá francofônico, em Montreal, província de Quéhec, era pois por nascimento 'un sujet britanique'. Seu pai era alemão, da tegião de antigo domínio francês. Sua mãe norueguesa também domiciliada no Canadá. Seus pais casaram-se no estado de Michigan, Estados Unidos. Em resumo, Erik Jayme acostumou-se desde logo ao chamado 'conflito das leis'. Isto é, quando a norma de mais de um ordenamento jurídico ou de mais de um Estado pode aplicar-se para regular a um só caso da vida privada. Acostumado à diferença e à pluralidade de culturas, optou pela nacionalidade alemã. Apesar do passaporte alemão, para ser professor em Mainz, Münster, Munique e Heidelberg teve que provar sua 'origem' e sua identidade cultural. Seus estudos refletem também esta abertura para o outro, o diferente, o estrangeiro, as diferentes culturas e línguas. Realizou seus estudos de graduação, mestrado e Doutorado em Direiro em Frankfurt, Munique, Pavia (Itália) e Berkeley (Estados Unidos).

\footnotetext{
- Ainda não publicada, gentilmente cedida por Christian Schindler e Niko Geiben do Intituto de Direito Estrangeiro da Universidade de Heidelberg, Alemanha, a quem agradeço.

${ }^{2}$ Revista Trimestraj de Direito Civil -RTDC, ano 1, vol. 3 jul./set. 2000, p. 289.
} 
Além do Direito, justamente o direito internacional privado, estudou também História da Arte, em Munique e aperfeiçoou-se em Portugal, onde aprendeu o português. Domina assim o alemão, o francês, o norueguês, o italiano, o inglês, o português e o croácio, além das línguas clássicas, latim e grego. De uma cultura impressionante, caracteriza-o a timidez, a simpatia e a precisão de um pensamento claro, aberto, profundo, sábio.

Um dos professores alemães de Direito Internacional Privado mais citados no mundo e no Brasil, Erik Jayme muito tem realizado pelo Direito brasileiro, especialmente através de seus inúmetos artigos publicados, suas palestras e cursos, os vários alunos e professores brasileiros da UFRGS que já orientou e, principalmente, através de suas renovadoras teorjas sobre toletância e humanismo no Direito. Fundador e grande incentivador da Associação Alemã-Lusirana de Juristas, tem criado pontes entre estas duas culturas, divulgando o direito e a cultura dos países de língua portuguesa.

Erik Jayme é membro da Academia das Ciências de Heidelberg, da Academia Nacional Italiana de Ciências, do Instituto Lombardo e da Academia de Ciências Austríaca. Foi Presidente do Instituto de Direito internacional, Diretor da Associação de Direito Comparado e é atualmente um dos rrês Academiciens ou Diretores de Direito Internacional Privado da Academia de Direito Internacional de Haia, além de Presidente da Associação Luso-Alemã de Juristas. Diretor da importante revista IPRAX, tem seus trabalhos publicados na Alemanha, Sứça, Áustria, França, Portugal, Noruega, Itália, Grécia, Hungria e Japão, assim como, ente nós, nos Estados Unidos, Canadá, México, Venezuela, Chile, Argentina e Brasil.

Na Alemanha, Erik Jayme recebeu todos os maiores prêmios que um jurista pode alcançar, inclusive o prêmio máximo de pesquisador de Baden-Würtemberg. Doctor honoris causa pela Universidade de Ferrata, Itália (1991); pela Universidade de Budapest, Hungria (2000) e pela Universidade de Montpellier, França (2001), hoje recebe o mesmo título honorífico das mãos de nossa magnífica Reirora Profa. Dra. Wrana Pannizzi.

Fundada em 18 de outubro de 1386, a Universidade de Heidelberg, Ruperto Carola, a primeira universidade em solo alemão, criada sob o modelo da Universidade de Paris, tem como emblema o leão do Palatinado segurando um livro em que se lê: semper apertus, sempre aberto. ${ }^{3} \mathrm{Na}$ bela Heidelberg, na Universitätsplatz, ao lado da Reitoria e do prédio central da Universidade, está localizado o Instituto de Direito Estrangeiro e Direito Internacional Privado de que é Diretor emérito, com sua maravilbosa biblioreca e amicável acolhida, que este encanta e forma pesquisadores do mundo inteiro. Domina a praça da universidade a estátuta de Palas Arena, a deusa da sabedoria, que saúda os

\footnotetext{
${ }^{3}$ Veja "Universitätsemblem", HAPP, Sabine e MORITZ, Werner, Die Ruprecht-Karls-Universität Heidelberg, Sutton Verlag: Erfurt, 2003.p. 2.
} 
estudantes a entrada da Universidade com a inscrição: Dem lebendigen Geist: ao espírito livre e vivo. ${ }^{4}$ Quando completou 600 anos, a Universidade de Heidelberg adotou o lema: "Da tradição ao futuro". Como sua alma mater, assim é Erik Jayme: aberto para o mundo, para o outto, para o diferente, unindo tradição e futuro, mas especialmente um espírito livre, vivo, original.

\section{II - UTOPIA}

Para o Programa de Pós-Graduação em Direito e para a Faculdade de Direito, este merecido título é motivo de júbilo. $O$ homenageado, homenageia-nos com sua simpatia e engajamento pela UFRGS e pelo Brasil. Para honrar devidamente este brilbante e renovador jurista, mister conhecer um pouco mais de sua doutrina que encanta e sensibiliza em um Direito normalmente tão frio, tão distanciado das pessoas.

Utopia, o lugar (tópos) que não está (ouk), o lugar que desde Thomas Morus ${ }^{6}$ queremos alcançar, a sociedade, o Estado Ideal que queremos re-construir. Qual é, pois, a utopia de Erik Jayme?

Dois são os eixos do pensamento deste grande jurista universal: alcançat a Igualdade entre Estados em uma sociedade globalizada, do pequeno ao grande país, criar e manter as bases do tratamento isonômico entre ordenamentos jurídicos de todos os Estados, aplicar as leis de países muçulmanos, europeus, americanos, asiáticos e da Oceânia, sem discriminações, lançando as bases para a paz, criando harmonia nas decisões, respeito pela sentença estrangeira e Justiça para os casos privados com conexões internacionais. O segundo eixo é a igualdade material e formal entre indivíduos. Iniciou por seus estudos em favor de uma autonomia de vontade da pessoa humana, como parte de seu direiro fundamental de desenvolver-se como pessoa e como bomo economicos, que resultaram na Resolução da Basiléia de 1991 do Instituto de Direito Internacional. Sua teoria evoluiu para frisar que o sujeito livre é aquele informado e protegido das pressões do mundo contemporâneo, dai a necessidade do Direito proteger os mais fracos, do Estado não se abster e proteger os vulneráveis, do Direito ser instrumento de reequilíbrio de situações estruturalmente diferentes. Para então, em 1995, no seu Curso Geral de Direito Internacional em Haia lançar a sua mais famosa teoria, a do Direito Internacional como um instrumento de respeito à identidade cultural da pessoa humana.

4 Doação do consulado norte-mericano para a Universidade, em 1930, SELLIN, Volker, SCHLECHTER, Franz, Dem Lebendigen Geist- Die Universität Heidelberg, Edition Braus, Heidelberg, 1993, p. 44.

"No original alemão: "Von Tradition zur Zukunft".

"Thiomas Morus escreveu em 1516 a sua obra "Utopia", veja sobre as origens da expressão Utopia, Kluge, Etymologissches Wörterbuch der deutschen Sprache, 23. Aufl., Waltex de Gruyter, Berlin, 1999 , p. 851 . 
Com seu realismo formidável, afirmava Erik Jayme em sua aula magna: "Temos de olhar o mal nos olhos, para poder vencê-lo." Assim, defendeu uma atualização necessária do Direito para acompanhat as mudanças, que a pós-modernidade impunha na sociedade, em velocidade impressionante no final do século XX. Este seu curso geral de Haia tem como título: "A identidade cultural e a integração econômica: o direito internacional privado pósmoderno". 7

Com a utilização da expressão sócio-filosófica "pós-moderno" 8 procura o Professor Erik Jayme demonstrar o caráter de mudança, de crise, de variabilidade (Umbruchcharakter) de nosso tempo e de nosso direito. ${ }^{9}$ A Tese de Jayme voltou-se inicialmente para os reflexos da pós-modernidade no direito internacional privado, ${ }^{10}$ como ramo mais sensível aos contatos humanos internacionais de nosso tempo ${ }^{11} \mathrm{e}$ as mudanças nos valores e modelos da sociedade. ${ }^{12}$ Mas a hipótese de rrabalho de Jayme, qual seja de que o direito, como expressão cultural de um povo, ${ }^{13}$ sofre reflexos maiores ou menores das mudanças valorativas, econômicas, históricas, éticas e mesmo religiosas de seu tempo, é válida também para outros ramos do direito. ${ }^{14}$ Assim, em

${ }^{7}$ JYME, Erik, Identité culturelle et intégration: Le droit internationale privé postmoderne - Cours général de droit international privé 1995, in Recueil des Cours de l' Académie de Droit International de la Haye, 1995,II, p. 33 e seg.

${ }^{B}$ Veja Lyotard, Jean-François, Das postmodeme Wissen - Ein Bericht, Peter Engelmann (Hrsg.), [Aus dem Französischen von Otto Pfersmann], Viena: Passagen Verlag, 1994, p. 13: "Dieses Wort [postmodern] ist auf den amerikanischen Kontinent, bei Soziologen und Kritikern gebräuchlich. Es bezeichnet den Zustand der Kultur nach den Transformationen, welche die Regeln der Spiele der Wissenschaft, der Literatur und der Kunste seit dem Ende des 19 Jahrhunderts getroffen haben." "Jayme, Erik, Identité culturelle et intégration: Le droit internationale privé postmoderne - Cours général de droit international privé 1995, in: Recueil des Cours de l'Académie de Droit International de la Haye, 1995,II, p. 36 e seg.

${ }^{30}$ Veja Jayme, Cours, p.28 e seg. e também Brilmayer, Lea "Post-modernism in American Choise of Law, Mélange Françôes Laurent, p. 695 e seg.

"Assim também conclui Ciuro Caldani, Miguel, Lineas de semejanza entre el Derecho Internacional Privado clasico y el Derecho de la postmodernidad, in Boletim del Centro de Investigaciones, UNR, nr. 6, 1997, p. 65 e seg.

${ }^{12}$ Assim Jayme, p. 2 (Avant-propos) e Sánchez Lorenzo, Postmodernismo y Derecho Internacional Privado, in Rev. Esp. de Der. Int., 1994, p. 557 e seg.

${ }^{13}$ Veja tamé necesariamente a las características de un deteminado momento histórico y evoluciona paralelanente a otras manifestaciones o productos de determinada cultura."...und p. 577 "El Derecho y el DIPr en particular se convierten entonces en un canal o medio de comunicación y de intercambio de valores hacia un mejor orden mundial."

${ }^{14}$ Neste sentido nossas conclusōes na Tese de Doutorado, Lima Marques, Claudia, "Das Subsidiaritätsprinzip in der Neuordnung des internationalen Adoptionsrechts - Eine Analyse des Haager Adoptionsübereinkommens von 1993 im Hinblick auf das deutsche und das brasilianische Recht", Verlag Für Standsamtwesen GmbH, Frankfurt-Berlin, 1997, p. 363. 
um tempo conhecido como pós-industrial, com uma filosofia pós-estruturalista e discursiva, ${ }^{15}$ uma era do vazio e de caos, ${ }^{16}$ de desregulamentação, de privatizações, ${ }^{17}$ de forte exclusão social, ${ }^{18} \mathrm{da}$ "euforia do individualismo e do mercado", ${ }^{19}$ era de globalização, de radicalismo tribal, de convivência e intolerância, de antinomias tão fortes que já se prevê o fim da história, a morte da ciência, ${ }^{20}$ of fim dos valores e outras catástroficas previsões para a nova era, ${ }^{21} \mathrm{em}$ resumo, em uma época de crise pós-moderna também o direito, ${ }^{22}$ como ciência próxima da realidade social ${ }^{23}$ e voltad a para a sociedade, ${ }^{24}$ estaria em crise e deve evoluir. ${ }^{25} \mathrm{Uma}$ crise de mudança, uma crise de crescimento. ${ }^{26}$

${ }^{15}$ Lyotazd, p. 19., afirma sobre a chamada sociedade pós-industrial e a cultura pós-moderna que: "Dieser Übergang beginnt spätestens mit dem Ende der fünfziger Jahre, das für Europa das Ende seiner Wiederaufbauphase bezeichnet. Es geht, entsprechend den Länder und innerhab dieser entsprechend dem Wirtschaftsbereich, mehx odex weniger schnell vor sich: daher die generelle Dischronie, die nicht leichı ein Gesamtbild abgibt." Já Harvey, David, The Condition of Postmodernity - An enquiry into the Origins of Cultural Change, Cambridge/Massachusetts 1994 , p.3 e 42 identifica os anos 60 e 70 como os anos desta mudança. Outros preferem o final da segunda. guerra mundial, os anos 50 como o inicio do movimento pós-moderno, assim Jameson, Frederic, PósModernismo - A lógica cultural do capitalismo tardio, Atica, São Paulo, 1996, p. 27.

${ }^{16}$ Assim o instigante Lipovetsky, Gilles, la era del vacio- Ensayos sobre el individualismo contemporáneo, Anagrama, Barcelona, 1996, em especial, p. 6 a 8.

${ }^{17}$ Assim Ciuro Caldani, Miguel, Privatización y Derecho Privado, in Boletim del Centro de Investigaciones, UNR, nr. 20, 1995, P. 119 e seg.

${ }^{8}$ Veja Tourraine, Alain, Uma Visão Crítica da Modernidade, in: Cadernos de Sociologia, vol. 5, pg. 36 e 37.

${ }^{9}$ Ghersi, Carlos Alberto, La Posmodernidad Juridica, Buenos Aires; 1995, p. 27: "No queda pues más que añadir, la posmodernidad es también la posmoralidad, es posolidaria, es sin duda le euforia del individualismo y el mexcado, gobernados desde la tumba de Bentham por el nuevo perfil utilitarista, alidai al placer y a la felicidad consumista."

${ }^{20} \mathrm{Como}$ explica Vattino em sua introdução, "O pós de pós-moderno indica, com efeito, uma despedida da modernidade...", veja Vattino, Gianni; O fim da modernidade- niilismo e hermenêutica na cultura pós-moderna, Martins Fontes, São Paulo; 1996, pg. VXr.

${ }^{21}$ Como afima Habermas, reconhecer, nomear ou denominar um fenômeno, como se faz com o pósmodernismo, significa se distanciar suficientemente deste e, mesmo, decretar o seu fim. Habermas nào se considera pós-moderno, está comprometido com os ideais da modernidade, chega a ironizar a freqüente utilização na literatura atual desta denominação "pós", inas, pot fím, reconhece a importância destes pensadores como sensiveis indicadores do "Zeitgeist", do pensamento e espirito atual a indicar uma mudança. Veja Habermas, p. 12.

${ }^{22}$ Segurdo Santos, Boaventura de Souza, Introdução a uma ciência pós-moderna, Graal, Rio de Janeiro; 1989, p. 11: "A época em que vivemos deve ser considerada uma época de transição entre o paradigma da ciéncia moderna e um novo paradigma, de cuja emergência se vão acumulando os sinais, e a que, à falta de melhor designação, chamo ciência pós-moderna."

${ }^{23}$ Veja pox todos, Gellner, Emest, pós-modernismo, razão e religiāo, Instituto Piaget, Lisboa, 1992, Pg. 11 e seg.

${ }^{24}$ Veja Harvey, p. 3 e seg. e Kaufmann, Arthur, Grundprobleme der Rechtsphilosophie - Eine Einführung in das rechtsphilosophische Denken, München 1994,p. $224 \mathrm{e} \mathrm{seg.}$

${ }^{29}$ Concorda também Lemouland, Jean-Jacques, Le pluralisme et le droit de la famille, postumodernité ou pré déclin, in Dalloz, 1997, nt. 18, Chronique, 1.05.97, p. 133 e seg.

${ }^{26}$ Veja Habermas, Jürgen, Nachmetaphysisches Denken, Ed.Suhrkamp, Frankfurt, 1992, p. 35. 
Identificar esta nova fase do direito ${ }^{27}$ e ajudar na reconstrução da ciência do Direito é o escopo da larga obra de Erik Jayme. Segundo o mestre, quatro seriam as características da cultura pós-moderna que têm reflexos no direito: o Pluralismo, a Comunicação, a Narração, o que Erik Jayme denomina de "le retour des sentiments" e a valorização dos direitos humanos. ${ }^{28}$

Pluralismo de fontes legislativas a regular o fato, pluralismo de sujeitos a proteger, por vezes difusos, como o grupo de consumidores ou os que se beneficiam da proteção meio ambiente, pluralidade de agentes ativos, em relações extremamente despersonalizadas, múltiplas, multifacetadas. ${ }^{29}$ Pluralismo na filosofia aceita, onde o diálogo é que legitima o consenso, ${ }^{30}$ onde os valores e principios têm sempre uma dupla função, o "double coding" pluralismo de fontes legislativas é hoje total, a ponto do diálogo das fontes nacionais e internacionais (mesmo soft law) nascer o novo direito. ${ }^{32}$

A comunicação é um valor máximo da pós-modernidade, associado a valorização extrema do tempo, do direito como instrumento de comunicação, de informação, como valorização do passar do tempo nas relações humanas, valorização do eterno e do transitório, do congelar momentos e ações para garantir a proteção dos mais fracos e dos grupos que a lei quer privilegiar. A comunicação é o método de legitimação (Sprachspiele), a ética e a filosofia é discursiva. ${ }^{33} \mathrm{O}$ consentimento legitimador,

\footnotetext{
${ }^{27}$ Zippelius, Reinhold, Rechstphilosophie, 3. Ed. Beck, Munique, 1994, p. 258.

${ }^{28}$ Jayme, Recueil des Cours, p. 36.

${ }^{29} \mathrm{Veja}$ sobre o pluralismo de fontes Friedman, Lawrence, The Republic of Choice - Law, Authority and Culture, Canbridge/Massachusetts, Harvard University Press, 1994.pg. 11.

30) Sobre o chamado "diálogo" das fontes, veja Jayme, Erik, Kulturelle Identität und das Kindeswoht im internationalen Kindschaftsrecht, Vortrag in der Tagung "Kinder im Recht" - Kindschaft und Völkerrecht im europäischen Kontext, Evangelische Akademie Tutzing, 20. Januar 1996, in IPRAX 1996 (4), p. 237-246 e sobre a internacionalidade e convivência de fontes nacionais e internacionais, van Loon, J.H.A, The Increasing Significance of International Co-operation for the Unification of Private International Law, in: Fouxty years on: the evolution of postwar private international law in Europe, Centrum voor Buitenlands Recht en Internationaal Privaatrecht (Hrsg.), Amsterdam 1990, p.105. ${ }^{31}$ Expressảo do direito pós-moderno, introduzida por Jayme, Recueil de Cours, p. 36 e seg. e que utilizo em meu livro de doutorado, orientado pelo grande mestre, Marques, Claudia Lima, Das Subsidiaritätsprinzip in der Neuordnung des internationalen Adoptionsrechts - Eine Analyse des Haager Adoptionsübereinkommens von 1993 im Hinblick auf das deutsche und das brasilianische Rechi Verlag für Standsamtwesen GmbH, Frankfurt-Berlin, 1997p. 124 e seg.

32 Jayme, Recueil des Cours, p. 247 e seg.

${ }^{33}$ Sobre o discurso e seus jogos escreve Lyotard, p. 36 e seg.: "Wenn Wittgenstein die Erforschung der Spracheab ovowiederaufnimut und seine Aufmerksamkeit auf die Wirkungen der Diskurse konzentriert, so nennt er die verschiedenen Arten von Aussagen, die er dabei auffindet und von welchen wir eben einige aufigezählt haben, Sprachspiele. Er gibt mit diesern Terminus zu verstehen, daß jede dieser verschiedenen Aussagenkategorien durch Regeln, die ihre Eigenschaften und ihren möglichen Gebrauch spezifizieren, determinierbar sein muß, genauso wie sich das Schachspiel durch einen Komplex von Regeln definiert, der die Eigenschaft der Figuren oder auch die exlaubte Art, sie zu bewegen, bestimnt."
} 
alerta o mestre, é só aquele informado e esclarecido. Comunicação é também internacionalidade das relações jurídicas e a re-valorização do direito internacional privado e das técnicas de harmonização e unificação das leis. ${ }^{34}$

A narração é a conseqüência deste impulso de comunicação, de in formação que invade a filosofia do direito e as próprias normas legais. ${ }^{35}$ Haveria um novo método de elaborar normas legais, não normas para regular condutas, mas normas que narram seus objetivos, seus princípios, suas finalidades, positivando os objetivos do legislador no sistema de forma a auxiliar na interpretação teleológica e no efeito útil das normas. Um belo exemplo são estas novas normas do dircito contemporâneo, que Erik Jayme denominou "normas narrativas". ${ }^{36} \mathrm{Com}$ tal fluidez e narratividade, o papel do intérprete e aplicador da leì se multiplica. Estas transformações na interpretação das leis e na filosofia do direito se tariam sentir também no aparecimento de movimentos contestatónios da dogmática tradicional, uma forte Jurispnudência de valores, estudos críticos e direito alternativo, em uma geral flexibilização, fragmentação e mesmo descaracterização do dogma ou crença no sistema geral de direito, ${ }^{37}$ mas também -positivamente- na grande influência representada pelos direiros fundamentais no direito privado..$^{38}$

Por firn, a quarta característica da cultura pós-moderna a afetar a ciência do direito é o que Jayme denomina "retour des sentiments". ${ }^{39}$ Seria, de um lado, a volta de uma certa "emocionalidade" no discurso jurídico, ${ }^{40}$ de outro lado é o impoderável, a procura de novos elementos sociais, ideológicos, religiosos e/ou fora do sisterna, que passam a incluir a argumentação e as decisões jurídicas, criando forte insegurança e imprevisibilidade quanto a solução a ser efetivamente encontrada. ${ }^{41}$

Dai a nessidade de uma reconstrução: olbar nos olhos e vencer!

O Leitmotive, elemento guia da teoria de Erik Jayme são os direitos humanos, como novos e únicos valores seguros a utilizar neste caos legislativo e destegulador, de codificações e microssistemas, de leis especiais privilegiadoras e de leis gerais imovíveis, de soft law e da

\footnotetext{
34 Jayme, Recueil des Cours, p. 247 e seg.

${ }^{35}$ Veja Jayme, Narrative Normen, p. 16 e seg. e as observaçōes de Sánchez Lorenzo, p. 558: “...el postmodemismo parece, antes que una filosofía del Derecho o una particular metodología jurídica en sentido amplio, una teoría del razonamiento juridico en la línea de la tópica o nueva retórica, partidaria de la narrative consistence frente a la normative consistence, en la distinción de $\mathbf{R}$. Dworkin retenida por E. Jayme."

${ }^{36}$ A definiçăo de normas narrativas é de Jayme, Erik, Narrative Normen im internationalen Privatund Verfahrensrecht, Mohr: Tübingen, 1993, p. 16.

${ }^{37}$ Assim Lorenzetti, Ricardo Luis, Fundamentos do Direito Privado, Ed. Revista dos Tribunais, 1998 , p. 280 e seg.

${ }^{38}$ Jayme, Recucil des Cours, p. 247 e seg.

${ }^{39}$ Jayme, Recueil des Cours, p. 36.

4"Veja a Draft Resolution for Buenos Aires elaborada pela International Law Assotiation (1994) que expressamente combate esta nova emocionalidade no direito e requer na adoção internacional: "The development of non-emotive standards for the application of the subsidiarity principle."

${ }^{41}$ Assim Jayme, Recueil des Cours, p. 261 : "Ce qui frappe, c'est le recours, dans les arrêts des tribunaux, à la référence aux sentiments des personnes intéressées comme raisons pour résoudte des conflits de lois."
} 
procura de uma equidade cada vez mais discursiva do que real. Os direitos humanos seriam as novas "normas fundamentais" ${ }^{42} \mathrm{e}$ estes direitos incluidos nas Constituições influenciariam o novo direito privado, a ponto do direito assumir um novo papel social, como limite da intervenção do Estado, como protetor do indivíduo e como inibidores de abusos, mas como incentivador de uma ação afirmativa do Estado para alcançar a equidade e a igualdade material entre todas as pessoas na nova sociedade multicultural.

\section{Observações finais}

Concluindo: perguntado sobre qual seria a herança do Direito privado para o século XXI, recomendou 'autonomia' e 'transparência', isto é, que o Direito do futuro vise preservar a autonomia e a liberdade dos indivíduos, assegurando a transparência e a informação, que são a chave da autodeterminação daquele que é sujeito (e não objeto) de direitos, o cidadão!

Sua preocupação filosófica com o bem estar dos indivíduos e de transformar o direito em um instrumento útil de proteção e de respeito à decisão livre deste plurifacetado 'sujeito pós-moderno', ficaram sintetizados em sua aula magna de abertura da Academia de Direito Internacional de Haia de 2000. Erik Jayme escolheu como tema 'a proteção da pessoa humana face à globalização e o direito'. $\mathrm{Na}$ entrevista ${ }^{43}$, que está incluída nos Cadernos da Pós-Graduação em homenagem à Etik Jayme, confessa: "tentei alcançar a proteção do indivíduo através de um reforço na autonomia deste, ao mesmo tempo, que se crie ese assegure direitos de informação." A crise da pós-modemidade é destruidora de muitos valores e certezas. Erik Jayme, com o brilhantismo que lhe é usual, procura reconstruir a ciência do Direito e assim alcançar a Equidade, a Liberdade, a Autonomia Privada e a Solidariedade. Uma Utopia, uma bela utopia que conquistou muitos seguidores no mundo.

Como afirma Heinz Peter Mansel, ${ }^{44}$ de um encontro com Erik Jayme rodos saimos enriquecidos, mais abertos, mais tolerantes, mais sábios. E até o abalado Direito, em plena crise da pós-modernidade, revisita a Utopia, preenche-se de novos valores do "Zeitgeisr" e renasce como instrumento de procura da Igualdade, da Justiça, do respeito ao outro, ao diferente, ao mais fraco, respeito e tolerância com a identidade cultural do outro. Saudar Erik Jayme é saudar o que há de bom no Direito: compromisso com a realidade e sonho de uma sociedade melhot!

Muito obrigado, lieber Doktorvater Erik Jayme!

por Claudia Lima Marques,UFRGS Porto Alegre (Brasil), 14.03.2003.

\footnotetext{
${ }^{42}$ Assim Lorenzerti, p. 249 e seg.

${ }^{43}$ Publicada pela primeira vez, con o título de "Diálogo com a Doutrina ", in Revista trimetral de Direito Civil -RTDC, ano 1, vol. 3 jul./set. 2000, p. 289.293

${ }^{44}$ Mansel, Heinz-Peter, Kulturelle Identìtät und Internationales Privatrecht, IPRAX 2003, p. 184.
} 